\title{
Impact of Human Capital on GNP Level
}

Željko Požega, Boris Crnković *

\section{Abstract}

It is possible to achieve faster rates of social growth, greater developement, a better standard of living and narrow the gap between rich and poor countries by changing a government's economic policies so that they emphasize investments in the developement of human potential. An increase in motivation, knowledge, levels of education and team organization, as well as a strengthening of citizens' moral, intellectual and social potential will, as the results of investigations quoted in this article show, bring faster growth of the Gross National Product (GNP). There is still a paradigm prevailing in south-eastern European countries to invest more in physical capital than in human capital. This paradigm is the reason that these countries continue to fall behind the most developed countries in the world.

Keywords: Human capital, Gross National Product, Human Developement Index, physical capital, economic developement, education, intelligence.

JEL: 015
DOI: 10.2478/v10033-008-0002-z

\section{Opening Considerations}

In this article, which consists of three parts, we wish to show the importance of human capital and its influence on the GNP of a given country. In the first part, we give a short outline of the theory of human capital and of the most significant writers who have dealt with this area and their insights. In the second part, we give methodology and data that were used in the investigation and analysis of different countries. In the third part, results are presented that comprise an analysis of the influence of different factors on the GNP of countries generally, as well as individual analyses of south-eastern European countries. The difference between expected and achieved GNP in the year 2003, with regard to available human, physical and financial resources of each country is also shown. The aim of this study is to test the hypothesis that human capital has the largest impact on a country's GNP level per capita.

\section{Theory of Human Capital}

The human factor is basic in achieving macroeconomic aims. The world today is marked by rapid and thorough changes in the field of business and management, where people and thier motivation, knowledge and creative and developement potentials are the most important factors for competitive advantage on the global market. The way in which we manage human potential is crucial for long term competitive ability, developement as well as the pure survival of any economic entity.

*Požega: Faculty of Economics in Osijek, Croatia, e-mail: osijek@efos.hr

*Crnković: Faculty of Economics in Osijek, Croatia 
Today, economics deals more with non-materialistic, that is, non-palpable resources, in which people, their knowledge and intellectual potential play a key role. Among these, human capital has recently become a special interest of economics, with an emphasis on knowledge as the most important resource, followed by information, intellectual property, experience and other factors that can be used in gaining wealth. Today, we exclusively need workers who add a certain value to every process they take part in, who bring value to their company. Because all property is almost equaly accessible to competitors, we should concentrate on the only property that is unique: top-quality workers. Only high motivation, permanent education, expert and flexible people and team work can bring about the efficient achievement of business and development aims.

A sample definition of human capital would be the sum of all human resource attributes that are relevant to the process of social reproduction (Milkovich, Boudreau, 1991.). The theory of human capital has continuously evolved from the middle of the 20th century. J. Mincer is the putative creator of this theory, despite the fact that $W$. Petty, who evaluated the population of England, as well as some other classical economists who emphasized the importance of human capital at the beginning of the 18th century, wrote about it before (Nadler L., Nadler Z.). A. Smith studied the renting fees of qualified and unqualified workers and stated that education and study are investment in human capital. Individual abilities learned from this education are, in his opinion, not only an aspect of individual worth but of global wealth as well (Walker). In his analysis of resource productiveness, K. Marx puts the expertise of workers first (Ivancevich). Marshall states that from among all the types of capital, human capital is the most essential: education is a national investment, while knowledge is "the most powerful production engine" (Ivancevich). Kuznets claims that the key for success in creating national income is the capital invested in people, and that this capital demands appropriate valorization (Milkovich, Boudreau, 1991.). Fisher highlights human capital when analyzing capital with return rates (Hansen, Knowles). J. Mincer sees human capital as an independent category of capital (Nadler L., Nadler Z.). Blaug classifies human capital into six categories: formal education, business training, acquiring information, job seeking, job migrations and investment in health (Nerdrum, Erikson). On the other side, Schultz sees investment in human capital as an alternative for investments in material production inputs because investing in education, one of the most important parts of human capital, brings returns several times larger than those from investing in equipment (Becker). Lauc divides human capital into moral capital (honor, emotional intelligence, motivation, responsibility, courage, tolerance, etc.), intellectual capital (mental abilities, rational intelligence, knowledge and skills, creativity) and social capital (resources in personal and business connections, working in teams) (Lauc).
Brooks and Nafukho define the development of human resources as a free system used in businesses for the development of every individual through training, with their career development tied to the development of the company as a whole (Walker). McLean defines human resource development as every process or activity that, in the short or long term, develops performance based on knowledge, expertise, productiveness and advances the goals of both the individual and a group, team, business, society, nation or even humanity (Dipietro, Anoruo). Gilley and Maycunich consider the development of human resources a means of facilitating organizational selfevaluation and change through managerial interventions and initiatives to improve the company's characteristics (Walker). Schmidt and Robinson discovered that social capital and mutual relationships have a positive effect on business transactions, production, trust and the ability to handle risk. The benefits of social capital include cutting transaction costs, because it improves cooperation between business clients and processes, improves negotiations and reduces business pressure, incorrect information and unnecessary paper work (Spicker). Salovey and Mayer define emotional intelligence as an intellectual process involved in recognizing, using, understanding and managing personal and other emotional states with the ability to channel these feelings into motivating, planning and achieving success (Hirsch). Emotional intelligence is part of the social capital development process within a company, and as a part of the wider concept of human resources development has a crucial effect on a business subject's productiveness.

While most classic and traditional economists focused on production, workers and financial capital, Romer emphasizes knowledge and technology and states that return rates on physical capital work according to the law of falling income, while return rates in an economy of knowledge and human capital rise and work according to the law of rising income (Romer). One characteristic of knowledge is that a person who has it constantly improves himself/herself, because with more knowledge he/she is more aware of his/her ignorance, which leads to improvement of one's abilities and a rise in social welfare and wealth. Romer also states that knowledge gives a return on investments and is a production factor, like physical capital, workers and raw material. According to the new theory of economic growth, additional work and capital are no longer the only necessities; new and better ideas incorporated in technological progress will generate economic growth as well. The traditional explanation of poverty in underdeveloped countries is their lack of sufficient natural resources or capital goods. Romer states that underdeveloped countries lack sufficient ideas and inventions, not natural resources. If poorer countries invest more in education and do not ruin their citizens' initiative towards creating new ideas, they will quickly gain advantage on the knowledge market and increase their return incomes. 


\section{Data and Methodology}

The results of this analyisis are based on research of the author, Željko Požega, that was conducted for his doctoral dissertation. The basis of this analysis is accessible, and the data collected on different statistic variables (out of 89 variables, 31 were chosen for this investigation by partial corelation) for 177 coutries worldwide both over an extended period (1975-2005, with a projection for 2015) and the year 2003 was analyzed in this article. The year 2003 was chosen because accessible data for that year were the most complete. Some of the variables analyzed in this article are accompanied by explanations of our methods of measurement and calculation. Other variables were calculated by simple statistic measures and are given in absolute numbers (population) or in relative numbers, such as percentage of GNP or of the whole population, or in relation to a citizen (per capita) (urban population, population under 15 , population over 65 , investments in health care, children mortality rate, investment in education, investment in preprimary and primary educatrion, investment in secondary education, investment in tertiary education, education rate for adults, number enrolled in primary education, number enrolled in secondary education, number of phone lines, number of mobile phone users, number of patents, export, import, direct foreign investments, national debt, investment in army, amount of electricity spent, number of women enrolled in tertiary education in relation to men, number of the population working, number of olympic medals in relation to GNP, GNP and inflation rate).

The Human Developement Index $(\mathrm{HDI})^{2}$ is calculated between 0 and 1 and considers the following measures: GNP per capita, literacy rate of adults, rate of school enrollment and expected age. An HDI between 1 and 0,8 is considered high, between 0,8 and 0,6 middle and between 0,6 and 0,4 low. The Gender-Ralated Developement Index measures gender equality in three dimensions included in HDI - length of life and level of health, education and aptness of life standard - adapted and calculated according to inequality between men and women. Educational levels are categorized as pre-primary, primary, secondary and tertiary and are in accordance with the International Standard Classification of Education (ISCED). The combined proportion of enrollment for primary, secondary and tertiary levels of education includes the number of students enrolled in primary, secondary and tertiary levels of education, irrespective of age, as a percentage of the school age population for these three levels. The Index of Press Freedom is measured by analyzing the number of journalists and free media

1 Official statistical data of UN, source: http://hdr.undp.org/ and http://unstats.un.org/unsd/

2 The Human Development Index (HDI) has been calculated by the authors. in a given country and the subjective analysis of the freedom of the press on a scale of 1 to 100 .

Neuron networks, which are used for analyzing data in this article, are a method of artificial intelligence structured according to the human brain. The reasons why neuron networks often yield better results than statistical methods lie in their ability to analyze insufficient data or hindered data, to cope with problems that do not have a clear single solution and to learn from past experience. Because of these advantages, neuron networks showed success in predicting series of financial data with high levels of variation and fluctuation. The results of many investigations have shown that neuron networks can solve almost any problem more efficiently than traditional modeling or statistical methods. It has been mathematically proven that three-layer neuron networks with limitlessly sensitive transmision function are able to approximate any non-linear function.

Neuron networks consist of two or more layers or groups of processing elements called neurons. The term neuron denotes the basic unit in the model of a neuron network designed for data processing. Neurons are connected in a network so that the exit of each neuron is the entrance to one or more other neurons. According to its direction, a neuron connection can be one-way or two-way, and according to intensity it can be excitatory or inhibitory. Neurons are grouped in layers. There are three main types of layers: incoming, hidden and outgoing. The incoming layer receives incoming data from the outside environment and sends them to one or more hidden layers. In the hidden layer, information from neurons is processed and sent to neurons of the outgoing layer. Information then travels backwards through the network and the weight values of connections between neurons are adapted according to the desired exit. The process in the network is repeated in as many iterations as necessary to reach the exit that is the closeset to the desired (real) exit. In the end, the network exit is presented to the user. Each neuron network goes through three operational phases: a training phase, a testing phase and an operational phase in which the neuron network is used in new cases with unknown results. The training rule represents a formula used to adapt the weight of connections among neurons. Among different trainig rules developed up to now, the most often used are: Delta rule, generalized Delta rule, Delta-Bar-Delta rule, extended Delta-Bar-Delta rule and Kohonen rule.

An analysis of data resulting from the calculation of the coefficient of multiple correlation and regression equations is also given in this article. The influence of independent variables on dependent variables is best 
expressed by multiple correlation, which we get as a linear correlation of zero order. To get the theoretical value of a certain statistical unit, we have to know the coefficient or determine the figure with an independent variable and a constant. In the system of equations with n-1 unknowns:

$$
\begin{aligned}
& b 1 r 11+b 2 r 12+\ldots+b n-1 r 1 n-1=r 1 n \\
& b 1 r 21+b 2 r 22+\ldots+b n-1 r 2 n-1=r 2 n \\
& b 1 r 31+b 2 r 32+\ldots+b n-1 r 3 n-1=r 3 n
\end{aligned}
$$

$b 1 r n-11+b 2 r n-12+\ldots+b n-1 \times r \times n-1=r n-1, n$

We get the coefficient of multiple correlation through the formula:

$$
R=\sqrt{\sum b_{i} r_{i n}}
$$

By entering the relevant data for each statistical unit we get the theoretical value for $y$ with the dependent equation:

$$
Y=A+B 1 X 1+B 2 X 2+B 3 X 3+\ldots+B n-1 X n-1
$$

which enables us, depending on the quantity of multiple correlation and the variability of the dependent variable, to predict the state of dependent variables within a certain margin of error. The prediction is more accurate as multiple correlation rises.

\section{Model of the Neuron Network}

The problem of analysing variables for countries in 2003 and the relation of the dependant variable (GNP per capita) and its change stipulated by the changes in independent variables is observed and analyzed by the Neurosolutions programme and the building of neuron networks. Through 30 incoming variables we attempted to measure their influence on one outgoing variable, GNP per capita; that is, the sensitivity of changes in dependent variables to changes in independent variables.

A sample of $\mathrm{N}=168$ layers is distributed in three parts. The network uses the first and biggest part for training (60\% of sample, $\mathrm{N}=101), 20 \%$ for crossvalidation ( $\mathrm{N}=33$ ) and $20 \%(\mathrm{~N}=33)$ for testing the data that were unavailable to the network in the phase of training and crossvalidation (so-called outside data). The neuron network that gives the best solutions was composed of these characteristics: a Multilayer Perception Network, a network algorithm 'backward widening', one hidden layer, a number of neurons in the hidden layers 1-20 (auto-optimalization preformed by the sample for crossvalidation is included), a transferable function in the hidden layer, the Sigmond Axon and Tangh Axon, the training rule Delta-Bar-Delta with momentum, step 1 , momentum 0,7 , one outgoing layer (with regard to one outgoing variable), a transferable function in the outgoing layer, a linear, training rule, momentum, step 1, momentum 0,7, maximum epoch number 1000 and Batch data processing.

The formula for the training rule that shows the influence of the training coefficient and momentum on adapting the weight in network is:

$$
\Delta w_{j i(k)}^{t}=\eta_{k} \cdot y_{c j} \cdot \varepsilon_{i}+\alpha_{k} \Delta w_{j i(k)}^{t-1}
$$

where $\eta$ is the training coefficient, $\alpha$ is momentum and $\mathrm{w}_{\mathrm{ji}}$ is the weight difference between neuron $\mathrm{j}$ and neuron $\mathrm{i}$, $\mathrm{y}_{\mathrm{c}} \mathrm{i}$ is output calculated in the network, and $\varepsilon$ is the margin of error.

While designing the network, the best result in the phase of network testing was achieved by changing different training parameters. The network made of 13 hidden neurons with 1000 training epochs and 0,7 momentum gives the best results. In this case the problem of an overtrained network arose, as a network with 2000 training epochs gives worse results than one with 1000 training epochs.

According to the MSE error formula:

$$
M S E=\frac{1}{n} \sum_{i=0}^{n-1}\left(t i-(o i)^{2}\right.
$$

Where ti is for calculated output, oi is desired (real) output and $i$ is the number of outgoing neurons in the network, the aim is to obtain a margin of error smaller than 0,01 so that the reliability of the investigation's results is acceptable. The MSE margin of error is explained as an average aberration between calculated and desired (real) output. In the analysis of data in this article, a mistake of 0,00025 means that the network output deviates 0,00025 from the real output. Error in the phase of crossvalidation after the 989th iteration no longer falls but rises. So the programme stores as the best network that which trains on 989th iterations and uses it in the testing phase.

\section{Analysis of GNP Sensitivity}

If we observe the results of the statistical analysis of the sensitivity of variables for countries in 2003 (see: Graph 1), we will see that if we take the GNP per capita as the dependent variable with a 0,98 correction coefficient and 
a 0,328 standard margin of error, the Human Developed Index variable with a $4 \quad 157,9$ coefficient (the variable was corrected for the value of GNP, i.e. standard of living (measured by PPP income)) has the highest sensitivity, its coefficient being four times higher than that of the second highest (GRDI) and much greater than most other variables. A very high sensitivity level was also shown with these variables: Gender Related Developement Index $(981,1)$, number of population capable of working $(717,1)$, number of olympic medals in relation to GNP $(510,2)$, number of women related to number of men enlisted in tertiary education (195,2). A slightly smaller coefficient was shown with these variables: investment in health care $(65,7)$, investment in army $(56,7)$, population over $65(54,99)$, population under $15(54,3)$, investment in education $(40,4)$, national debt $(38,2)$, direct foreign investment $(18,5)$, investment in tertiary education $(14,4)$, investment in pre-primary and primary education $(13,96)$ and mixed correlation for primary, secondary and tertiary education $(13,1)$. The rest of the variables have low coefficients and did not show significant sensitivity levels towards the dependent variable, GNP per capita. The results of this investigation show the causes that brought about greater differences in the stages of developement between countries and that will deepen the gap between the life standards in rich and poor coutries if any, especially the poor ones, do not make significant changes and place an emphasiss on investment in people.

It is interesting that in analysing the equations of dependant variables for countries for 2003 we can see that, with a 0,95 multiple corelation coefficient, out of 177 analysed counties 137 in that year achieved real GNP per capita lower than expected GNP per capita; that is, almost 137 countries with existing human, physical and financial resources in the given year should have achieved a higher level of GNP per capita. Also, only one country achieved real GNP per capita equal to the expected GNP per capita in the given year, Slovenia. Furthermore, only 30 countries in the world achieved GNP per capita greater than expected in the given year. We can say that 30 countries in the world achieved finacial results greater than expected with their human, physical and financial resources.

Among the countries that achieved GNP per capita lower than the expected GNP per capita, the greatest gaps were in Burundi (almost 50 times lower than expected), the Democratic Republic of Congo (46 times lower) and Ethiopia (39 times lower). Among the countries that achieved GNP per capita higher than expected, the most successful were Luxembourg (3,5 times higher than expected), Switzerland (2,8 times higher), Denmark and Ireland (2,5 times higher), USA (2,4 times higher), Norway, Japan and Holland (2,2 times higher), Great Britain (2,1 times higher), Austria and France ( 2 times higher) and Belgium and Germany (1,8 times higher). With a slightly less favourable relation between real and expected GNP per capita were Australia, the Bahamas, Cyprus, Eritrea, Finland, Greece, Hong Kong,
Iceland, Italy, Israel, Canada, Kuwait, New Zealand, Portugal, Singapore, Spain and Sweden.

If we put the data for south-eastern European countries in the given regresion variables equation for 2003 we will see that, for example, Albania, with its human, physical and financial resources should have achieved a GNP per capita of $\$ 7941$; this is around 4 times higher than the GNP per capita achieved, which was $\$ 1933$. Furthermore, with its human, physical and financial resources, Bulgaria should have had \$13 474 GNP per capita in 2003, which is 5 times higher than what it achieved, \$ 2539 . Bosnia and Herzegovina should have had \$9533 GNP per capita in 2003 , almost 6 times higher than its actual GNP per capita, \$ 1684 . Croatia should have had $\$ 12633$, and it achieved only \$ 6 479, roughly half. Macedonia should have had \$10 596 but it achieved only $\$ 2277$ ( 5 times lower). Romania should have had \$ 12119 , but it achieved \$ 2619 (4,5 times lower). Finally, Turkey should have had $\$ 9265$, but it achieved $\$ 3$ 399 GNP per capita in that year, which is 3 times lower than expected. The positive examples were Greece and Cyprus. Greece, with its human, physical and financial resources, should have achieved a GNP per capita $\$ 13759$, which is lower than its GNP per capita of $\$ 15608$. Cyprus, with its human, physical and financial resources should have achieved a GNP per capita $\$ 12878$, which is lower than its GNP per capital, which was $\$ 14$ 786. Data for Serbia and Montenegro, i.e. ex Yugoslavia, are not available for 2003.

\section{Synthesis of the Results}

The results of statistical analysis on the sensitivity of variables for countries in 2003 show that the highest sensitivity or influence on GNP per capita was Human Developement. This is the index variable that shows the developing level of human resources in a given country. It was followed by the Gender-Related Developement Index variable, which shows development level in terms of gender; after it came the total working population, the number of olympic medals related to GNP, relation of women to men in tertiary education, etc.

Analysis of the equation of dependent variables for countries in 2003 showed that out of 177 analyzed countries, 137 achieved real GNP per capita lower than expected. 137 coutries, with their existing human, physical and finacial resources in the given year, should have achieved a higher GNP per capita level. Only 30 countries in the world achieved higher GNP per capita than expected in that year, meaning that 30 countries in the world achieved a financial result higher than expected with their human, physical and financial resources. All south-eastern European countries analyzed in this article achieved a lower real GNP per capita with their existing human, physical and financial resources in the given year than expected, with the exceptions of Greece and Cyprus. 
It is possible to achieve higher and faster coefficients of social developement, a higher level of development and a better life standard, as well as reduce the gap between rich and poor countries, by changing their economic policies so that countries give priorities to investment in people and in developing human potential. Raising the level of motivation, knowledge, education and team organisation, and strengthening and improving the moral, intellectual and social capital of a population will lead to faster GNP growth, as the results of this investigation show. The prevailing paradigm in south-eastern European countries is to invest more in physical capital than human capital. It is for this reason that the region has fallen behind the most developed countries in the world. [.

\section{References}

Becker, S., "Responding to poverty: the politics of cash and care"

Longman, cop., London, New York, 1997.

Bradshaw, M., J., Dymond, J., P., White, G., W., "Contemporary world regional geography : global connections, local voices"

McGraw-Hill, New York, 2004.

Davey, K. J., "Investing in regional development: policies and practices in EU candidate countries"

Local Government and Public Service Reform Initiative, Open Society Institute, cop., Budapest, 2003.

Delleck, H., Von den Bosch, K., De Lathouwer, L., "Poverty and the Adequacy of Social Security in the $\mathrm{EC}^{\prime \prime}$ Avebury, Aldershot, 1995.

Fellmann, J., D., Getis, A., Getis, J., "Human geography: landscapes of human activities" second edition, Wm. C. Brown Publishers, cop., Dubuque, 1990.

Grin, F., Daftary, F., "Nation-building, ethnicity and language politics in transition countries"

Local Government and Public Service Reform Initiative, Open Society Institute: European Centre for Minority Issues, cop., Budapest, 2003.

Hirsch, F., "Social limits of Growth"

Harvard University Press, Cambridge, 1976.

"International Journal of Social Economics", Dipietro, W. R., Anoruo, E., "GDP per capita and its challengers as measures of happiness"

Emerald Group Publishing Limited, 10/2006.

Ivancevich, J. M., "Human Resource Management" sixth edition, Irwin, 1995.

"Journal of Economic Studies", Hansen, P., Knowles, S., "Human capital and returns to scale"

Emerald Group Publishing Limited, 2/1998.
"Journal of Intellectual Capital", Nerdrum, L., Erikson, T., "Intellectual capital: a human capital perspective" Emerald Group Publishing Limited, 2/2001.

"Journal of Intellectual Capital", Romer, P. M., "Economic growth"

Emerald Group Publishing Limited, 1/2004.

Lauc, A., "Metodologija društvenih znanosti"

Sveučilište J. J. Strossmayera u Osijeku, Pravni fakultet Osijek, 2001.

Milkovich, G. T., Boudreau, J. W., “Human Resource Management"

sixth edition, Irwin, Boston, 1991.

Milkovich, G. T., Boudreau, J. W., "Personnel/Human Resource Management"

Fifth edition, Business Publications, Inc., Plano, Texas, 1988.

Nadler, L., Nadler, Z., "Developing Human Resources" Third edition, Jossey-Bass Publishers, San Francisco, Oxford, 1991

Nikolovska, N., Sundać, D., "Globalization and economic downfall of countries in transition" Magor, Skoplje, 2002.

Spicker, P., "Poverty and Social Security: Concepts and Principles"

Routledge, London and New York, 1993.

"The World Bank Research Department", Almeida, R., “Local Economic Structure and Growth" International Economics Department, Commodity Policy and Analysis Unit, 08/2005.

Walker, J. W., "Human Resource Strategy" McGraw-Hill, Inc., 1992. 


\section{Attachment}

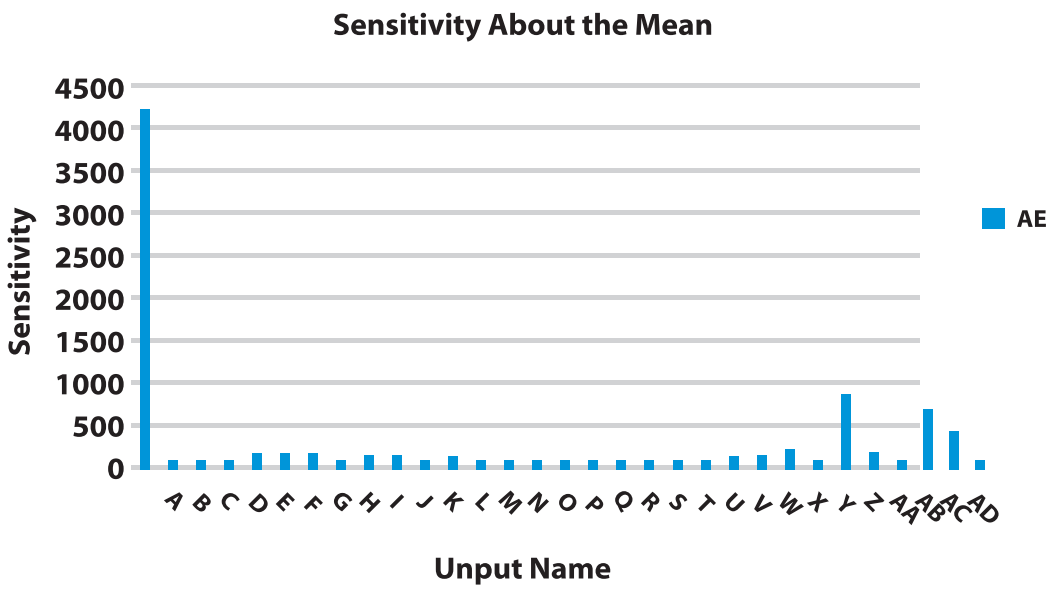

\begin{tabular}{|c|c|}
\hline Sensitivity & $\mathrm{AE}$ \\
\hline A & 4157.94043 \\
\hline B & 13.14852715 \\
\hline C & 0.597405791 \\
\hline D & 5.691743374 \\
\hline $\mathrm{E}$ & 54.33771133 \\
\hline $\mathrm{F}$ & 54.9911232 \\
\hline G & 65.72640991 \\
\hline $\mathrm{H}$ & 4.420273781 \\
\hline I & 40.41278839 \\
\hline J & 13.96146297 \\
\hline $\mathrm{K}$ & 1.182915211 \\
\hline L & 14.40869522 \\
\hline M & 1.700477242 \\
\hline $\mathrm{N}$ & 0.598946631 \\
\hline $\mathrm{O}$ & 6.348370552 \\
\hline$P$ & 1.571432114 \\
\hline Q & 3.663119793 \\
\hline $\mathrm{R}$ & 0.326730281 \\
\hline $\mathrm{S}$ & 19.66231918 \\
\hline T & 10.18229961 \\
\hline$U$ & 18.51408386 \\
\hline V & 38.21792984 \\
\hline W & 56.74648285 \\
\hline $\mathrm{X}$ & 0096917048 \\
\hline Y & 981.1262207 \\
\hline Z & 195.17453 \\
\hline AA & 2.310561419 \\
\hline$A B$ & 717.137146 \\
\hline AC & 510.0514526 \\
\hline$A D$ & 5.621172428 \\
\hline
\end{tabular}

Graph 1. Analy1 sis of GNP sensitivity for countries in the world in 2003.
A - Human Developement Index (by partial correlation corrected for GNP value i.e. standard of living (measured by PPP income)

B - Combined relation for primary, secondary and tertiary education

C - Population

D - Urban population

E - Population under 15

F - Population over 65

G - Investment in health care

$\mathrm{H}$ - Children mortality rate

- Investment in education

J - Investment in pre-primary and primary education

$\mathrm{K}$ - Investment in secundary education

$\mathrm{L} \quad$ - Investment in tertiary education

$M$ - Adult educational rate

$\mathrm{N}$ - Number enrolled in primary education

O - Number enrolled in secondary education

$P$ - Number of phone lines

Q - Number of mobile phone users

$R$ - Number of patents

S - Import

$T$ - Export

$U$ - Direct foreign investments

V - Total debt

W - Investment in army

$X$ - Electricity spent

Y - Gender-Related Developement Index

Z - Number of women related to the number of men enrolled in tertiary education

$A A$ - Index of freedom of the press

$A B$ - Number of population capable of working

$A C$ - Number of olympic medals

$A D$ - Inflation rate

\section{Legend - Graph 1.}

